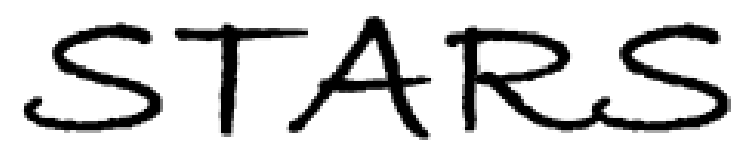

University of Central Florida

STARS

$1-1-2013$

\title{
Recovery torque modeling of carbon fiber reinforced shape memory polymer nanocomposites
}

He Shen

University of Central Florida

Yunjun Xu

University of Central Florida

Fei Liang

Jihua Gou

Bob Mabbott

Find similar works at: https://stars.library.ucf.edu/facultybib2010 University of Central Florida Libraries http://library.ucf.edu

This Article is brought to you for free and open access by the Faculty Bibliography at STARS. It has been accepted for inclusion in Faculty Bibliography 2010 s by an authorized administrator of STARS. For more information, please contact STARS@ucf.edu.

\section{Recommended Citation}

Shen, He; Xu, Yunjun; Liang, Fei; Gou, Jihua; and Mabbott, Bob, "Recovery torque modeling of carbon fiber reinforced shape memory polymer nanocomposites" (2013). Faculty Bibliography 2010s. 4684.

https://stars.library.ucf.edu/facultybib2010/4684

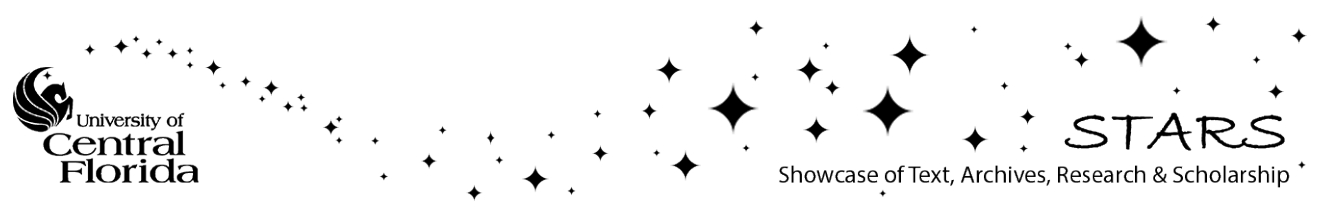




\section{Recovery torque modeling of carbon fiber reinforced shape memory polymer nanocomposites}

Cite as: Appl. Phys. Lett. 103, 201903 (2013); https://doi.org/10.1063/1.4829937

Submitted: 04 October 2013 . Accepted: 29 October 2013 . Published Online: 12 November 2013

He Shen, Yunjun Xu, Fei Liang, Jihua Gou, and Bob Mabbott
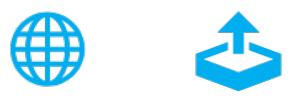

View Online

Export Citation

\section{ARTICLES YOU MAY BE INTERESTED IN}

Thermal modeling and coefficient identification of shape memory polymer nanocomposites structure

Applied Physics Letters 106, 081907 (2015); https://doi.org/10.1063/1.4913804

Artificial muscles made of chiral two-way shape memory polymer fibers

Applied Physics Letters 109, 183701 (2016); https://doi.org/10.1063/1.4966231

Synergic effect of carbon black and short carbon fiber on shape memory polymer actuation by electricity

Journal of Applied Physics 104, 104917 (2008); https://doi.org/10.1063/1.3026724

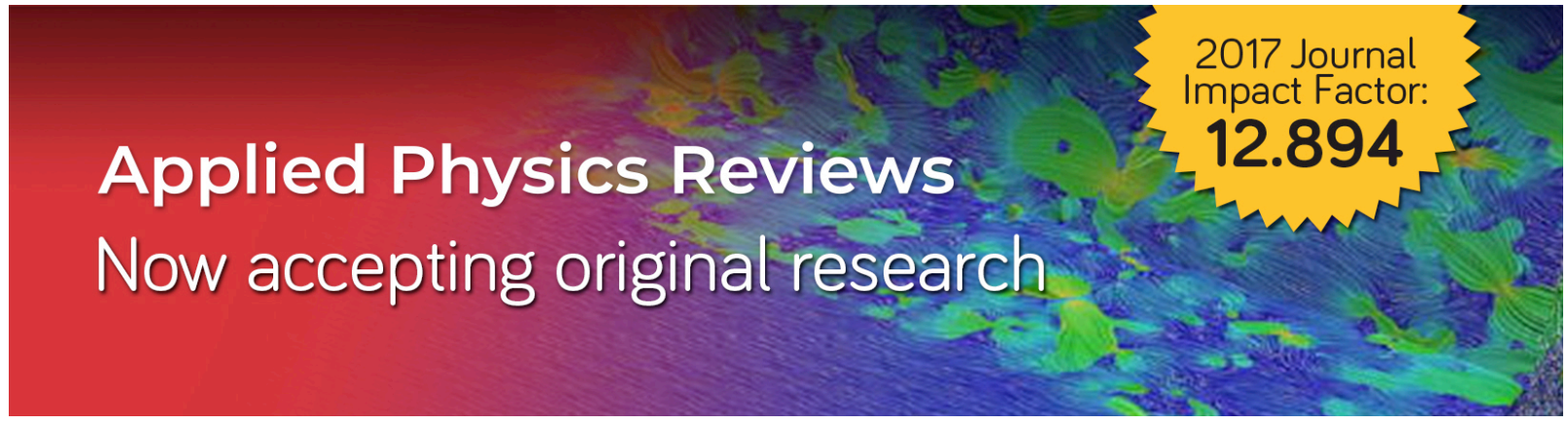




\title{
Recovery torque modeling of carbon fiber reinforced shape memory polymer nanocomposites
}

\author{
He Shen, ${ }^{1}$ Yunjun Xu, ${ }^{1, a)}$ Fei Liang, ${ }^{2}$ Jihua Gou, ${ }^{2}$ and Bob Mabbott ${ }^{3}$ \\ ${ }^{1}$ Dynamics and Controls Laboratory, Department of Mechanical and Aerospace Engineering, \\ University of Central Florida, Orlando, Florida 32816, USA \\ ${ }^{2}$ Composite Materials and Structures Laboratory, Department of Mechanical and Aerospace Engineering, \\ University of Central Florida, Orlando, Florida 32816, USA \\ ${ }^{3}$ HB Polymer Company, Sarasota, Florida 34243, USA
}

(Received 4 October 2013; accepted 29 October 2013; published online 12 November 2013)

Carbon fiber and carbon nanofiber paper (CF\&CNFP) can be incorporated into shape memory polymers (SMPs) to increase electrical conductivity and allow high speed electrical actuation with a low power. This paper studies the interactions among the recovery torques of CF\&CNFP and SMP and the gravity torque during the shape recovery process. The proposed recovery torque model in a SMP CF\&CNFP based structure is validated by experimental data obtained using a recently developed low cost, non-contact measurement testbed. (C) 2013 AIP Publishing LLC. [http://dx.doi.org/10.1063/1.4829937]

Shape memory polymers (SMPs) are smart materials that can memorize permanent shapes and recover to them under external stimulus such as light, heat, and electric power. $^{1,2}$ Being capable of recovering large strains, SMP materials have great potential to be used in many emerging applications such as deployable structures, textile, surface decoration, and biomedical devices. ${ }^{3,4}$

To date, SMP materials are only capable of memorizing a limited number of shapes. ${ }^{1}$ These shapes are not flexible after they were manufactured. Thus, it is desirable if SMP materials can be controlled precisely to intermediate shapes in a convenient and cost effective approach. To achieve precision controls of the shape recovery process, a model that can predict the recovery torque is necessary. Much attention has been brought to the development of constitutive models ${ }^{4-8}$ relating strain and stress for thermal-driven, water-driven, or light-driven SMPs. ${ }^{9}$ Also, research has been conducted to enhance the mechanical properties of SMPs. ${ }^{10}$ However, high computational cost, unknown and possibly changing material properties, and simplification assumptions used in deriving these constitutive models make them less attractive from the practical perspective of real-time shape recovery controls.

The SMP sample studied here was manufactured through the following steps. The $500 \mu \mathrm{m}$ thickness carbon nanofiber paper (CNFP) was made by the infiltration method. The carbon nanofibers (CFs) were dissolved into $400 \mathrm{ml}$ deionized water and then sonicated using a high intensive probe sonicator $(1000 \mathrm{~W})$ for $30 \mathrm{~min}$ in a 11 beaker. In order to disperse CFs evenly, $4 \mathrm{ml}$ of surfactant Triton- $\times 100$ was added into the solution. Then, the solution was sonicated for another $30 \mathrm{~min}$ and cooled down to the room temperature. After that, the as-prepared suspensions were sonicated for 2 min and immediately transferred into the filtration system. The CNFP was fabricated by filtration method. After the CNFP was fabricated, an autoclave was used to make fiber reinforced SMP nanocomposites. The resin used is the

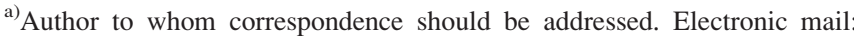
Yunjun.Xu@ucf.edu. Tel.: +1 407823 1745. Fax: +1 4078230208
}

polyurethane based SMP (MP5510), which is provided by SMP Technologies, Inc., in Japan. SMP resin part A and part $\mathrm{B}$ were dried at $50^{\circ} \mathrm{C}$ under a $-27 \mathrm{inHg}$ vacuum atmosphere for $3 \mathrm{~h}$. Part A and part B were mixed for 2 min at $60 \mathrm{rpm}$ and then poured into a die, which was dried for more than 3 $\mathrm{h}$ at $70^{\circ} \mathrm{C}$. The vacuum bag tooling was closed and the -27 inHg vacuum is applied immediately. A 15 psi pressure was applied for $5 \mathrm{~min}$ then increased up to 50 psi. The temperature increased to $75^{\circ} \mathrm{C}$ after $5 \mathrm{~min}$. The curing process ended after $3 \mathrm{~h}$.

The structure of manufactured SMP CF\&CNFP is composed of three layers (Fig. 1): (i) CNFP (very thin and enables the electrical actuation); (ii) CF (improves mechanical properties such as strength and modulus); and (iii) SMP matrix.

When above the glass transient temperature and at low deformation levels, SMPs exhibit a fully recoverable linear elastic behavior. ${ }^{11}$ The recovery torque is modeled using the Hooke's law ${ }^{12}$ as $\tau_{S}=k_{S}\left(\theta_{S}-\theta\right)$, in which $\theta_{S}$ and $\theta$ are the permanent and current deflection angles, and $k_{S}>0$ is the spring coefficient. Compared to the CF layer, the CNFP layer is thin and soft, the contribution of which to the recovery torque is relatively low. Thus, the recovery torques of $\mathrm{CF}$ and CNFP are treated together as $\tau_{C}=k_{C}\left(\theta_{C}-\theta\right)$, where $\theta_{C}$ and $k_{C}>0$ are the neutral point and spring coefficient. The recovery process (Fig. 2) is governed by

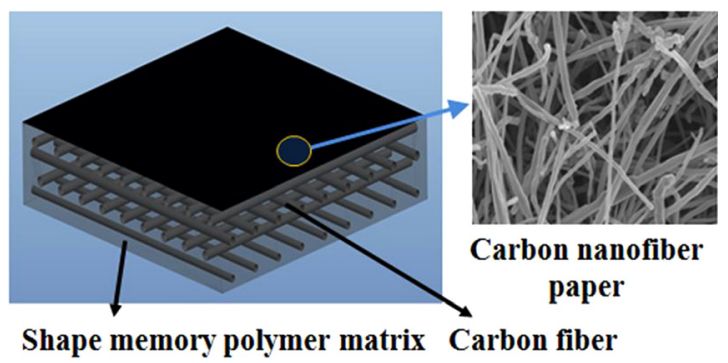

FIG. 1. Three layered SMP CF\&CNFP structure. 


$$
I \dot{\omega}=\tau_{S}+\tau_{C}-m g l \cos \theta,
$$

where $I, \omega, m, g$, and $l$ are the moment of inertia, angular velocity, mass, gravitational coefficient, and torque arm. The overall recovery torque $\tau_{T}=\tau_{S}+\tau_{C}$ of SMP CF\&CNFP can be calculated using $\tau_{T}=I \dot{\omega}+m g l \cos \theta$. There is an equilibrium point $\theta_{N}$ in Eq. (1): when $\theta=\theta_{N}$, the resultant torque is zero and $\dot{\omega}=0$.

A low cost testbed (Fig. 3) is developed to measure dynamic behaviors of CF\&CNFP in recovery. Two Microsoft LifeCam ${ }^{\circledR}$ webcams (resolution: $1920 \times 1080$, frame rate: $30 / \mathrm{s}$, and field of view: $75^{\circ}$ ) are used to monitor geometry information. Image processing software is programmed to calibrate the cameras (obtaining the intrinsic and extrinsic parameters), detect the color dots painted on the material surface, reconstruct the $3 \mathrm{D}$ coordinates of these dots, and calculate the deflection angle in real-time. The working frequency is $2 \mathrm{~Hz}$. The angular velocity and angular acceleration of the structure are calculated using the deflection angle through the five-point stencil method. ${ }^{13}$ The MLX90614 infrared thermometer ${ }^{\circledR}$ (resolution: $0.02{ }^{\circ} \mathrm{C}$ and accuracy: $0.5^{\circ} \mathrm{C}$ ) measures the temperature near the axis where the material is rotating about. It is worth noting that the recorded temperature is not on the surface of the material, instead it is about $7 \mathrm{~mm}$ below the material surface (in the vertical direction) and $16 \mathrm{~mm}$ relative to the rotation axis (in the horizontal direction). Therefore, the temperature recorded is below the actual material surface temperature. An ASC712 current sensor ${ }^{\circledR}$ (sensitivity: 185 mv/A) measures the current going through the material.

In each experiment, the material is first bended to $0^{\circ}$ when its temperature is above the glass temperature, and then cooled down. After that, a constant voltage is applied to heat the material until the material is deflected to its permanent shape. The material is not loaded in its recovery.

After removing experiment outliners, the following 33 recovery processes are recorded: 7 cases for $20 \mathrm{~V}$ and $30 \mathrm{~V}$ and 4 cases for $15 \mathrm{~V}, 17.5 \mathrm{~V}, 22.5 \mathrm{~V}$, and $25 \mathrm{~V}$. The averaged deflection angular velocity and deflection angle profiles for all these cases are shown in Fig. 4: (i) When the recovery starts and the deflection angle $\theta<\theta_{N}$, the recovery torques from SMP and CF\&CNFP are positive but decreasing. Since the recovery torque magnitude drops in a quicker fashion than that of the gravity torque, the overall angular acceleration $\dot{\omega}$ decreases but still maintains positive. (ii) When $\theta=\theta_{N}$, the recovery torque of SMP is positive. The resultant torque is zero, the angular acceleration is zero, and the angular velocity reaches its maximum value. The maximum angular velocities for different experiments all happen around $60^{\circ}$ (Fig. 4), which means that the equilibrium point

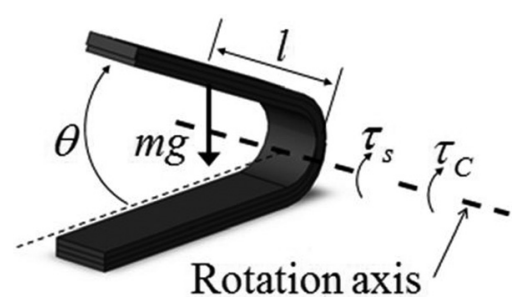

FIG. 2. Free body diagram in the recovery process.

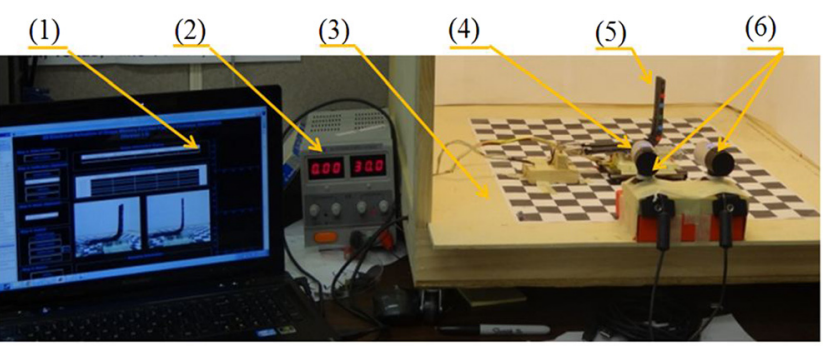

(1) Software (2) Power Supply (3) Power Control Circuit (below the platform) (4) Temperature Sensor (5) SMP CF \& CNFP (6) Webcams

FIG. 3. Non-contact dynamic torque measurement testbed.

$\theta_{N}$ is largely affected by the strain instead of how quick the energy is injected into the nanocomposite structure. (iii) When $\theta_{N}<\theta<\pi / 2$, the recovery torque of SMP keeps decreasing but still positive. The gravity torque decreases to zero. The recovery torque of CF\&CNFP may decrease (in the positive direction) or increase (in the negative direction), but the resultant torque starts to increase in the negative direction. (iv) When $\pi / 2<\theta<\theta_{\infty}$, the gravity torque increases in the positive direction, and the recovery torque of SMP decreases but is still in the positive direction. However, the recovery torque of $C F \& C N F P$ increases in the negative direction, which results in a net decrease in the magnitude of the negative angular velocity (Fig. 4).

The spring coefficient of SMP is almost constant when the material temperature is $15^{\circ} \mathrm{C}$ above or below the glass temperature. ${ }^{14}$ In the glass transient stage, it can be modeled as the following exponential function: ${ }^{14}$

$$
k_{S}=k_{S, 0} \exp \left\{c_{1}\left[T_{G} /\left(c_{2} T\right)-1\right]\right\}, \quad k_{S, 0}>0 .
$$

The mechanical property of CF\&CNFP is stable and thus $k_{C}$ is assumed to be constant. ${ }^{15}$

The nonlinear constrained optimization solver in MATLAB (fmincon) is used to identify the coefficients in the proposed model (Eq. (2)). For our 33 experiment scenarios, $\theta_{S}=150^{\circ}$ is assumed. The objective function to be minimized is

$$
J=\sum_{k=1}^{N} \frac{\left|I \dot{\omega}_{k}+m g l \cos \theta_{k}-k_{S}\left(\theta_{S}-\theta_{k}\right)-k_{C}\left(\theta_{C}-\theta_{k}\right)\right|}{\left|I \dot{\omega}_{k}+m g l \cos \theta_{k}\right|}
$$

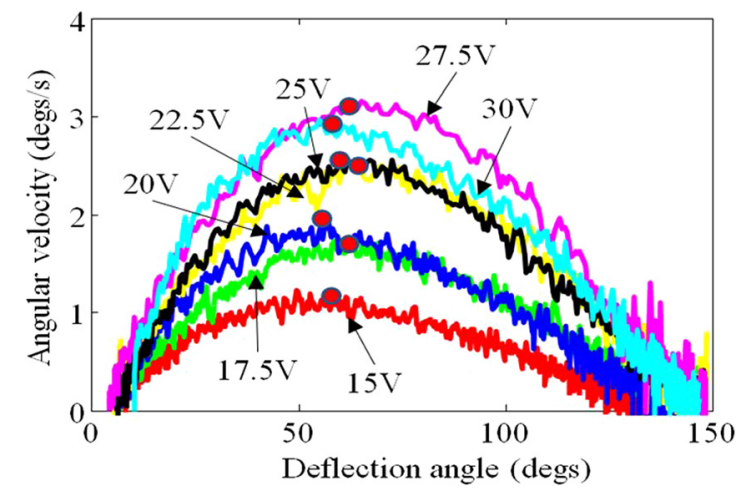

FIG. 4. Averaged deflection angle and angular velocity. 


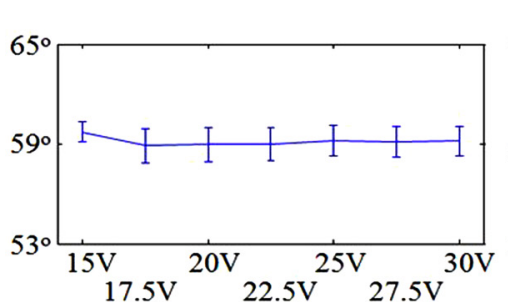

(a) $\theta_{N}$

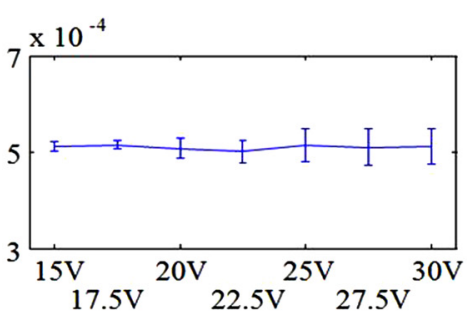

(b) $k_{S}$

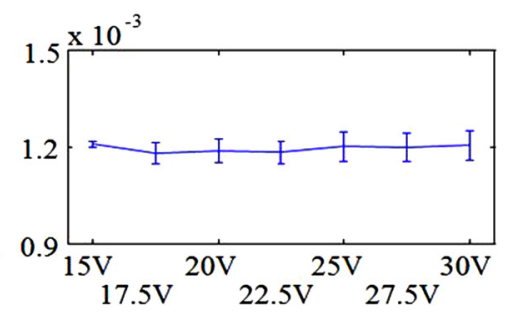

(c) $k_{C}$

FIG. 5. Identified equilibrium point and coefficients in the proposed torque model for different voltage inputs.

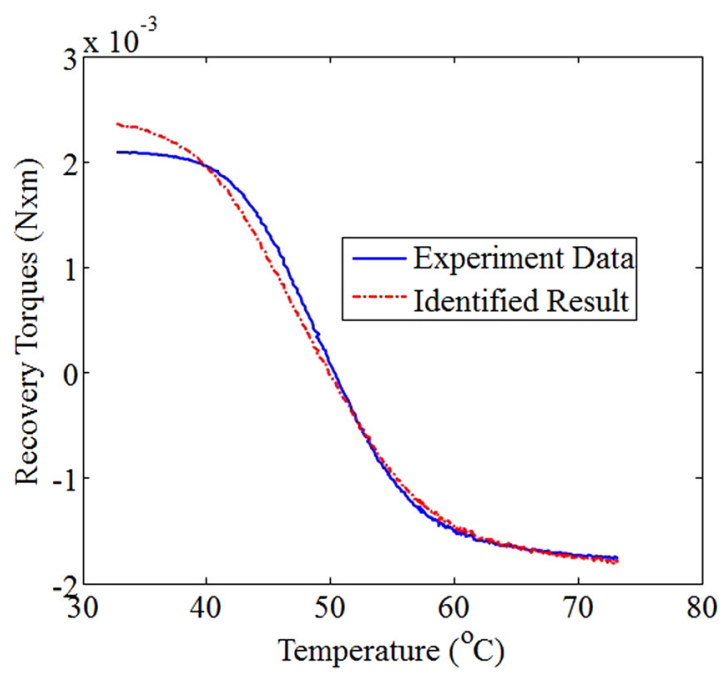

FIG. 6. Recovery torques of SMP CF\&CNFP.

where $N$ is the number of measurements in each case, and subscript $k$ denotes the $k^{\text {th }}$ experiment data. As mentioned in Ref. 14 and validated here, both constant and exponential spring coefficient cases are tried in the parametric identification. The constraint bounds of spring coefficients are carefully tuned such that the identified parameters are consistent, and the residuals in the performance index are minimized and consistent for all 33 cases.

The following arguments can be made about the parametric identification results. (i) The residuals for all 33 experiments are small in both the constant and exponential spring coefficient cases (between $4.32 \%$ and $6.78 \%$ ). (ii) In Fig. 5(a), the equilibrium point $\theta_{N}$ is consistent within a range of $\left[59^{\circ}, 61^{\circ}\right]$. (iii) The spring coefficients of recovery torques are consistent (Figs. 5(b) and 5(c)). (iv) The identified $c_{1}$ in Eq. (2) is almost zero $\left(10^{-16}\right)$, which validates the observation in Ref. 11 that the mechanical properties of SMP are nearly constant when the temperature is above the glass transition region. (v) Figure 6 shows one identified result that matches well with the experimental data. The temperature value in the $\mathrm{x}$-axis is the temperature of the point about $7 \mathrm{~mm}$ below the material surface (in the vertical direction) and $16 \mathrm{~mm}$ relative to the rotation axis.

The reasons that the identified data do not perfectly match the experimental data include: (i) the accuracy of vision, temperature, and current sensors is not high enough; (ii) the mechanical-thermal-electrical properties of SMP CF\&CNFP may degrade along with repeated experiments; and (iii) the mass, moment of inertia, and length are not perfectly measured.

Although the identified model is not $100 \%$ accurate, it can help (i) researchers in material processing and synthesis to predict the strength of recovery torques and how they are interacting between each other; (ii) control engineers to design robust/adaptive controllers to drive precisely not only the SMP CF\&CNFP deflection angle but also the morphing speed.

Two major contributions of this letter are summarized here. First, a low cost, non-contact testbed is developed to measure dynamic recovery torque, geometry, electrical, and temperature information in SMP nanocomposites recovery process. Second, a recovery torque model is proposed and validated by experimental data. As shown in Ref. 14 and validated by the parameters' identification, the spring coefficient of CF\&CNFP is assumed either to be an exponential function or constant depending on whether it is inside of the glass transition period or not. It is found that there is an equilibrium point where three torques are balanced. The proposed model can be used in controller designs to achieve precision shape recovery processes, as well as guide the SMP nanocomposites material processing to achieve a desired recovery dynamic response.

The first four authors (He Shen, Yunjun Xu, Fei Liang, and Jihua Gou) would like to thank the HB Polymer Company, LLC for financial support.

${ }^{1}$ T. Xie, Nature 464, 267 (2010).

${ }^{2}$ H. Lu and W. M. Huang, Appl. Phys. Lett. 102, 231910 (2013).

${ }^{3}$ C. M. Yakacki and K. Gall, Adv. Polym. Sci. 226, 147 (2010).

${ }^{4}$ J. Leng, D. Zhang, Y. Liu, K. Yu, and X. Lan, Appl. Phys. Lett. 96, 111905 (2010).

${ }^{5}$ J. Hu, Y. Zhu, H. Huang, and J. Lu, Prog. Polym. Sci. 37, 1720 (2012).

${ }^{6}$ B. L. Volk, D. C. Lagoudas, and D. J. Maitland, Smart Mater. Struct. 20, 094004 (2011).

${ }^{7}$ P. Ghosh and A. R. Srinivasa, Int. J. Eng. Sci. 49, 823 (2011).

${ }^{8}$ Y. Liu, K. Gall, M. L. Dunn, A. R. Greenberg, and J. Diani, Int. J. Plast. 22, 279 (2006).

${ }^{9}$ J. S. Sodhi and I. J. Rao, Int. J. Eng. Sci. 48, 1576 (2010).

${ }^{10}$ C. Zhang, H. Wei, Y. Liu, H. Tan, and Z. Guo, High Perform. Polym. 24, 702 (2012).

${ }^{11}$ R. D. Siskind, "Model development for shape memory polymers," Ph.D. dissertation (North Caroline State University, 2008).

${ }^{12} \mathrm{~J}$. M. Gere and B. J. Goodno, Mechanics of Materials (Cengage Learning, 2012).

${ }^{13}$ M. Abramowitz and I. A. Stegan, Handbook of Mathematical Functions with Formulas, Graphs, and Mathematical Tables (Dover Publications, NY, 1970).

${ }^{14}$ H. Tobushi, K. Okumura, S. Hayashi, and N. Ito, Mech. Mater. 33, 545 (2001).

${ }^{15}$ K. Gall, M. Mikulas, N. A. Munshi, F. Beavers, and M. Tupper, J. Intell. Mater. Syst. Struct. 11, 877 (2000). 